\title{
Spatial and Object-Based Attention Modulates Broadband High-Frequency Responses across the Human Visual Cortical Hierarchy
}

\author{
Ido Davidesco, ${ }^{1,2}$ Michal Harel, ${ }^{3}$ Michal Ramot, ${ }^{1,2}$ Uri Kramer, ${ }^{4,5}$ Svetlana Kipervasser, ${ }^{4,5}$ Fani Andelman, ${ }^{7}$ \\ Miri Y. Neufeld, ${ }^{4,5}$ Gadi Goelman, ${ }^{6}$ Itzhak Fried, ${ }^{7,8}$ and Rafael Malach ${ }^{3}$ \\ ${ }^{1}$ Interdisciplinary Center for Neural Computation, Hebrew University, Jerusalem 91904, Israel; ${ }^{2}$ Edmond \& Lily Safra Center for Brain Sciences, Hebrew \\ University, Jerusalem 91904, Israel; ${ }^{3}$ Department of Neurobiology, Weizmann Institute of Science, Rehovot 76100, Israel; ${ }^{4}$ EEG and Epilepsy Unit, Tel Aviv \\ Sourasky Medical Center, Tel Aviv 64239, Israel; ${ }^{5}$ Sackler School of Medicine, Tel Aviv University, Tel Aviv 69978, Israel; ${ }^{6}$ Medical Biophysics, Hadassah \\ Hebrew University Medical Center, Jerusalem 91120, Israel; ${ }^{7}$ Functional Neurosurgery Unit, Tel Aviv Sourasky Medical Center, Tel Aviv 64239, Israel; and \\ ${ }^{8}$ Department of Neurosurgery, David Geffen School of Medicine, UCLA, Los Angeles, California 90095
}

One of the puzzling aspects in the visual attention literature is the discrepancy between electrophysiological and fMRI findings: whereas fMRI studies reveal strong attentional modulation in the earliest visual areas, single-unit and local field potential studies yielded mixed results. In addition, it is not clear to what extent spatial attention effects extend from early to high-order visual areas. Here we addressed these issues using electrocorticography recordings in epileptic patients. The patients performed a task that allowed simultaneous manipulation of both spatial and object-based attention. They were presented with composite stimuli, consisting of a small object (face or house) superimposed on a large one, and in separate blocks, were instructed to attend one of the objects. We found a consistent increase in broadband high-frequency $(30-90 \mathrm{~Hz})$ power, but not in visual evoked potentials, associated with spatial attention starting with V1/V2 and continuing throughout the visual hierarchy. The magnitude of the attentional modulation was correlated with the spatial selectivity of each electrode and its distance from the occipital pole. Interestingly, the latency of the attentional modulation showed a significant decrease along the visual hierarchy. In addition, electrodes placed over high-order visual areas (e.g., fusiform gyrus) showed both effects of spatial and object-based attention. Overall, our results help to reconcile previous observations of discrepancy between fMRI and electrophysiology. They also imply that spatial attention effects can be found both in early and high-order visual cortical areas, in parallel with their stimulus tuning properties.

\section{Introduction}

Selective visual attention is a multidimensional process in which the attended stream of information is processed preferentially relative to the ignored streams (O'Craven et al., 1999; Kanwisher and Wojciulik, 2000). One of the puzzling aspects in the attention literature is the discrepancy between electrophysiological and fMRI findings (Boynton, 2011). Human fMRI studies consistently revealed strong attentional modulation of early visual cortex, including V1 (Brefczynski and DeYoe, 1999; Gandhi et al., 1999; Kastner et al., 1999; Martinez et al., 1999; Somers et al., 1999). Single-unit and local field potentials recordings in nonhuman primates, on the other hand, yielded more mixed results

Received July 4, 2012; revised Oct. 29, 2012; accepted Nov. 9, 2012.

Author contributions: I.D. and R.M. designed research; I.D., M.R., U.K., S.K., F.A., M.Y.N., G.G., and I.F. performed research; I.D. and M.H. analyzed data; I.D. and R.M. wrote the paper.

This study was supported by the Kimmel Award for Innovative Research and Bikura Grant to R.M. and by the WIS-Ichilov Fund to R.M. and I.F. We thank the participants for volunteering to take part in the study, as well as D. Yossef, S. Nagar, and C. Yosef and the EEG technicians for assistance at the Tel Aviv Medical Center.

The authors declare no competing financial interests.

Correspondence should be addressed to Prof. Rafael Malach, Department of Neurobiology, Weizmann Institute of Science, Rehovot 76100, Israel. E-mail: rafi.malach@gmail.com.

DOI:10.1523/JNEUROSCI.3181-12.2013

Copyright $\odot 2013$ the authors $\quad 0270-6474 / 13 / 331228-13 \$ 15.00 / 0$
(Roelfsema et al., 1998; Fries et al., 2002; Maunsell and Cook, 2002; Reynolds and Chelazzi, 2004; Buffalo et al., 2010; Buffalo et al., 2011; Bosman et al., 2012). Intriguingly, an electrocorticography (ECoG) study in humans found no effect of spatial attention in V1 and V2 (Yoshor et al., 2007). However, this study only examined evoked responses, time-locked to the stimuli, whereas attentional modulation might be more pronounced in the induced broadband high-frequency (HF) responses, also termed broadband gamma responses (Tallon-Baudry et al., 2005; Lachaux and Ossandón, 2009; Engell and McCarthy, 2010). These responses are also better coupled to the fMRI BOLD signal (Engell et al., 2012). The picture has been further complicated by the recent report that attention, paradoxically, reduces stimulusdriven gamma-band responses in primate V1 (Chalk et al., 2010).

Another open question concerns the nature of spatial attention in high-order visual cortex. Several fMRI studies have shown spatial attention effects in high-order visual areas in tasks that required attending the left versus right visual fields. However, it is not clear whether such attentional effects extend to size/eccentricity (Avidan et al., 2003) given the significant contribution of size/eccentricity information in ventral occipitotemporal cortex (Levy et al., 2001). 
Table 1. Patient characteristics

\begin{tabular}{lllllll}
\hline Patient ID & Gender & $\begin{array}{l}\text { Age } \\
\text { (years) }\end{array}$ & Handedness & $\begin{array}{l}\text { Implanted } \\
\text { hemisphere }\end{array}$ & $\begin{array}{l}\text { No. of } \\
\text { implanted } \\
\text { electrodes }\end{array}$ & $\begin{array}{l}\text { Seizure } \\
\text { localization }\end{array}$ \\
\hline 28 & F & 40 & Right & RH & 44 & Right aT \\
29 & F & 28 & Right & Bilateral & 56 & Right T \\
32 & F & 36 & Left & Bilateral & 47 & Left mF \\
33 & F & 14 & Right & LH & 28 & Left T \\
35 & F & 12 & Right & RH & 63 & Right F-P \\
36 & F & 37 & Right & RH & 54 & Right P-T-0 \\
40 & F & 33 & Right & Bilateral & 60 & Right T \\
41 & M & 36 & Right & RH & 68 & Right F-T \\
43 & F & 16 & Right & LH & 62 & Left P-T-0 \\
46 & M & 48 & Right & RH & 68 & Right T \\
& & & & & 550 & \\
\hline
\end{tabular}

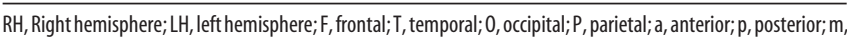
medial.

Here, we aimed at addressing these issues using ECoG recordings in epileptic patients. ECoG provides a rich electrophysiological signal, which can be decomposed to various oscillation frequencies. Previous studies have shown that rhythmic narrow-band gamma synchronization is modulated by attention (Fries et al., 2001; Fries et al., 2002; Buffalo et al., 2011; Womelsdorf and Fries, 2011; Bosman et al., 2012). Here we focused on studying attentional modulation of broadband HF responses, which likely reflect the underlying population firing rates (Kreiman et al., 2006; Nir et al., 2007; Manning et al., 2009; Burns et al., 2010; Ray and Maunsell, 2011) and/or postsynaptic potentials (Miller et al., 2009) and compared them with visual evoked potentials (VEPs).

We report four main observations: (1) we found selective modulation of broadband HF power (but not of VEPs) associated with attention starting with V1/V2 and continuing throughout the cortical hierarchy; (2) attentional modulation was correlated to stimulus selectivity on the one hand, and to the cortical hierarchy, on the other hand; (3) the latency of the attentional modulation was reduced along the cortical hierarchy; and (4) eccentricity-related attentional effects were not confined to early visual areas but extended to high-order areas as well.

\section{Materials and Methods}

\section{Subjects and recordings}

Ten patients ( 2 males, 9 right-handed, age: $30 \pm 3.9$, mean \pm SEM; Table 1) with pharmacologically intractable epilepsy, monitored for potential surgical treatment, participated in the present study. Two patients did not have any visually responsive electrodes and therefore were excluded from further analysis. Two additional patients performed nonstandard tasks: one performed a categorization task and the second performed a 1-back memory task at the cued location. Unlike the standard task, in the categorization task the object categories were mixed within a given block. Therefore, this patient was excluded from the object-based attention analysis. Excluding the patient who performed the 1-back task did not alter any of the main results; he was thus included in the final analyses. Three patients were children, 12-16 years of age (Table 1 ). There were no significant differences between children and adults in the latency of the broadband HF response or in its amplitude or spectral content. Therefore, data obtained from children were combined in the final analysis. The recordings were conducted at the Tel Aviv Sourasky Medical Center, Israel. All patients provided fully informed consent according to the institutional Committee for Activities Involving Human subjects.

Each patient was implanted with 28-68 intracranial electrodes (Adtech), which were arranged in $1 \mathrm{D}$ strips and $2 \mathrm{D}$ grids. Each contact was 2 $\mathrm{mm}$ in diameter with $1 \mathrm{~cm}$ separation. The location and number of electrodes were based solely on clinical criteria. Recordings were monopolar and were referenced to an extracranial electrode. In 6 patients, the signal was sampled at a rate of $200 \mathrm{~Hz}$ (Grass Technologies) and in the other 4 patients, at a rate of $256 \mathrm{~Hz}$ (CareFusion). Stimulus-triggered electrical pulses were recorded along with the ECoG data for precise synchronization of the stimuli with the neural responses.

The recordings were conducted at the patients' quiet bedside. Stimuli were presented via a standard LCD screen, and keyboard responses were recorded for measurement of behavioral performance.

\section{Electrode localization}

Computed tomography (CT) scans following electrode implantation were coregistered to the preoperative MRI using BioImagesuite (www. bioimagesuite.org). Electrodes were then identified in the CT, and their coordinates were normalized to Talairach coordinates (Talairach and Tournoux, 1988) and rendered in BrainVoyager software in two dimensions as a surface mesh, enabling precise localization of the electrodes. For joint presentation of all patients' electrodes, electrode locations were projected onto a cortical reconstruction of a healthy subject from a previous fMRI study of our group.

\section{Experimental design}

Attention experiment. The patients were presented with composite stimuli, consisting of a small circle (radius of $\sim 1.7^{\circ}$ of visual angle) containing a line drawing of a face or a house, superimposed on a large circle (radius of $\sim 9^{\circ}$ of visual angle) containing a line drawing from the other category (Fig. 1). To avoid higher information content in the large images compared with the small ones, we generated the large images by enlarging the small images by a factor of 5.3. In separate blocks, the patients were cued to attend the small or the large objects. Within a given block, the object category presented at each eccentricity was constant (i.e., there were 2 types of blocks: a face within a house and a house within a face). The cue appeared for $2 \mathrm{~s}$ and consisted of a single object marked by a red frame. The cue informed the patients both which eccentricity to attend and which specific target they are required to detect in the following block, which started after a jittered fixation period of 3-5 s. Each block consisted of 8 stimuli, each of which was presented for $250 \mathrm{~ms}$ followed by $1250 \mathrm{~ms}$ fixation. The task of the patients was to detect the target stimulus at the cued location by pressing a mouse button while maintaining fixation. To keep patients attentive, the target stimulus appeared 2-4 times in each block. There were 10 blocks of each condition, each lasting $12 \mathrm{~s}$, interleaved with $3 \mathrm{~s}$ fixation periods and divided into two runs. The same composite images appeared in both conditions in a different order; thus, the retinal input at both attentional conditions was identical. Importantly, this paradigm allowed manipulating not only spatial attention but also object-based attention. Because the object categories were always mixed (e.g., a face within a house) and because within a given block the object category presented at each eccentricity was constant, attending a certain eccentricity (center vs periphery) inevitably also meant attending a certain object category. However, the counterbalance of object categories and eccentricities allowed a $2 \times 2$ design, isolating the eccentricity and object category effects.

Stimulus control experiment. This experiment was identical to the attention experiment, except that the stimuli contained either a small or a large object (Fig. 1, stimulus control experiment) while the patients performed a categorization task (face or house).

\section{Eye movement controls}

Inadvertent shifts in eye position may affect ECoG responses, particularly in spatially selective retinotopic responses. Our experimental paradigm was designed to minimize eye movements by two means. First, stimuli were presented briefly $(250 \mathrm{~ms})$ and terminated before a substantial fraction of saccadic eye movements could be executed. Second, the concentric circular presentation that was used in our study (Fig. 1) was less susceptible to trigger reflexive eye movements toward one side of the visual field compared with tasks in which the participant has to attend the left or the right visual fields. In addition, in two patients, eye positions were recorded at $500 \mathrm{~Hz}$ using a remote infrared eye tracking system (SR Research Eyelink 1000). Trials in which eye position exceeded the boundaries of the small image were counted in each attentional condition. We also compared the values of the attentional modulation with and without these trials. Finally, we repeated the main analyses using a short time window of $100-300 \mathrm{~ms}$ post-stimulus onset (as opposed to the 
standard 50-600 ms time window), in which it is less likely that eye movements took place.

\section{Definitions of electrode ensembles}

Visually responsive electrodes. Following Fisch et al. (2009), these electrodes were defined as those with short- to mid-latency responses (up to $250 \mathrm{~ms}$ post-stimulus onset) to visual stimuli in the stimulus control experiment.

Early visual electrodes. These were defined based on two criteria: (1) geodesic distance (i.e., distance along the cortical surface) of $\leq 40$ $\mathrm{mm}$ from the occipital pole (Murphey et al., 2009); and (2) response latency of $\leq 100 \mathrm{~ms}$ (Fisch et al., 2009).

V1/V2 electrodes. Following Yoshor et al. (2007), electrodes were assigned to V1/V2 according to their anatomical locations based on well-established definitions of V1/V2 borders from fMRI studies in healthy participants (Sereno et al., 1995; DeYoe et al., 1996).

\section{Data analysis}

Behavioral data. For each patient and for each attentional condition, we computed the mean reaction time (RT), accuracy rate (number of hits divided by the number of target-present trials) and false alarm rate (i.e., percentage of cases in which the patient responded even though the target was absent). In computing the mean RT, only hits were considered and trials in which the RT deviated from the mean RT by $>2$ SD were excluded. In computing the accuracy and false alarm rates, no trials were excluded. However, blocks with more than one error were excluded from the neural data analysis.

Neural data: preprocessing and broadband HF responses calculation. In the preprocessing stage, potential $50 \mathrm{~Hz}$ electrical interference was removed from the raw signals using a linear-phase notch infinite impulse response filter of order 4 . In addition, each electrode was averagereferenced by subtraction of the averaged signal of all the electrodes, thus discarding non-neuronal contributions (Privman et al., 2007). It could be argued that subtracting the averaged signal of all electrodes, including visually responsive electrodes, might have affected the results. However, note that in all 10 patients only a minority of the electrodes were visually responsive ( $11 \pm 3 \%$, mean \pm SEM, range: $0-25 \%)$. Furthermore, we reanalyzed the entire dataset, subtracting the mean signal of nonvisual electrodes only. For each one of the 4 stimulus and attentional modulation indices (see Individual electrode analysis), we computed the correlation between the values obtained by referencing of all electrodes versus referencing of nonvisual electrodes only. All the correlation coefficients were nearperfect (spatial selectivity index: $r=0.98, p<10^{-47}$; spatial attention index: $r=0.94, p<10^{-30}$; object selectivity index: $r=0.99, p<10^{-50}$; object attention index: $r=0.98, p<10^{-42}$ ). Therefore, it is unlikely that subtracting the mean response of all electrodes, including visual electrodes, affected our results.

The broadband HF responses were computed in the following manner: for each trial, Fourier transform amplitude spectrum with Hanning window tapering was calculated in a $160 \mathrm{~ms}$ sliding window with a step size of $5.96 \mathrm{~ms}$. Next, the baseline power spectrum was computed by averaging a prestimulus period of $250 \mathrm{~ms}$ across all trials from all conditions. The time-frequency decomposition of each trial was then divided by this baseline and averaged across trials (Lachaux et al., 2005). Finally, the broadband HF responses were calculated as the average of the spectrogram's frequency rows in the range of $30-90 \mathrm{~Hz}$ (Vidal et al., 2010). The lower bound of this range was set to $30 \mathrm{~Hz}$ because of reduction in spectral power at lower frequencies after visual stimulation, termed event-related desynchronization (Fig. 2F) (Crone et al., 2006). The upper bound $(90 \mathrm{~Hz})$ was dictated by the sampling rate $(200 \mathrm{~Hz}$ in most

\section{Attention experiment}
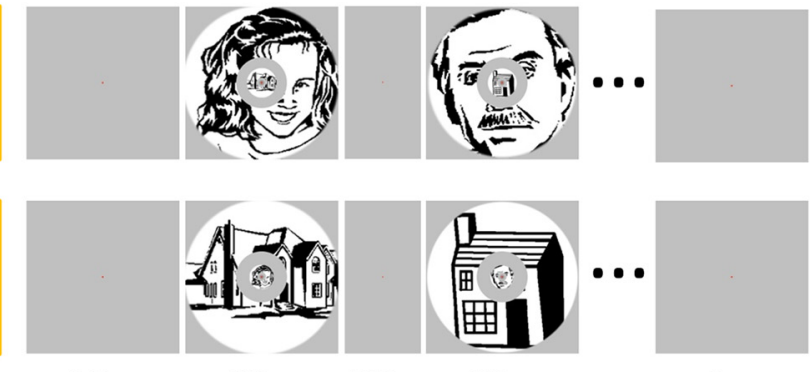

$3-5 \mathrm{sec}$

$250 \mathrm{~ms}$

$1250 \mathrm{~ms} \quad 250 \mathrm{~ms}$

$3 \mathrm{sec}$

Time

C

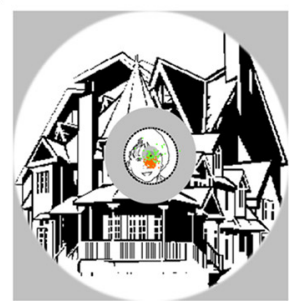

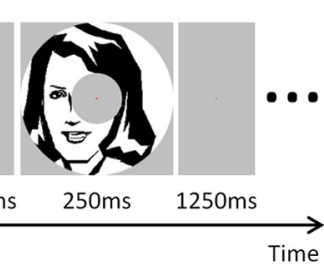

$1250 \mathrm{~m}$

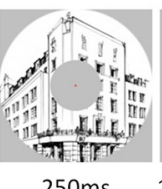

$250 \mathrm{~ms}$ Figure 1. Experimental paradigm and eye tracking. A, Attention experiment: the patients viewed composite stimuli, consisting
of a small object (line drawing of either a face or a house) superimposed on a large one. In separate blocks, the patients were cued to attend the small or the large object while maintaining fixation and performing a target detection task. $\boldsymbol{B}$, Stimulus control zation task (face or house). C, Example of eye fixations measured in one of the patients during attend center (orange) and attend at all the fixations were well confined within the borders of the small image.

patients). Note that within this range the power increases were rather uniform in sign. Unless stated otherwise, for statistical tests, the broadband HF response was quantified as the area under the curve (AUC) in a time window of 50-600 ms post-stimulus onset. This time window was chosen because of the long latencies of attentional effects in V1/V2 reported in previous studies (Buffalo et al., 2010).

Data processing was carried out using MATLAB (The Mathworks) and EEGLAB (Delorme and Makeig, 2004). Geodesic distance between each electrode and the occipital pole was measured using the CARET software (Van Essen et al., 2001).

Individual electrode analysis. For each visual electrode, we computed 4 indices based on the mean broadband HF AUC of each experimental condition. Two indices captured the stimulus modulation assessed in the control experiment:

$$
\begin{aligned}
& \text { Spatial selectivity idx }=\frac{\text { small }- \text { large }}{\text { small }+ \text { large }} \\
& \text { Object selectivity idx }=\frac{\text { face }- \text { house }}{\text { face }+ \text { house }}
\end{aligned}
$$

And analogically, two indices referred to the attentional modulation in the main experiment:

$$
\begin{aligned}
& \text { Spatial attention idx }=\frac{\text { attend_small }- \text { attend_large }}{\text { attend_small }+ \text { attend_large }} \\
& \text { Object attention idx }=\frac{\text { attend_face }- \text { attend_house }}{\text { attend_face }+ \text { attend_house }}
\end{aligned}
$$

These indices were also computed as $\mathrm{d}^{\prime}$ values by replacing the denominator of these formulas by the SD of the broadband HF AUC across trials in each experimental condition. For example, the spatial selectivity d' was computed as follows:

$$
\frac{\text { Mean }(\text { small })-\text { Mean(large })}{\text { Mean }(\text { std }(\text { small }), \text { std(large }))}
$$


A Early vs. high visual

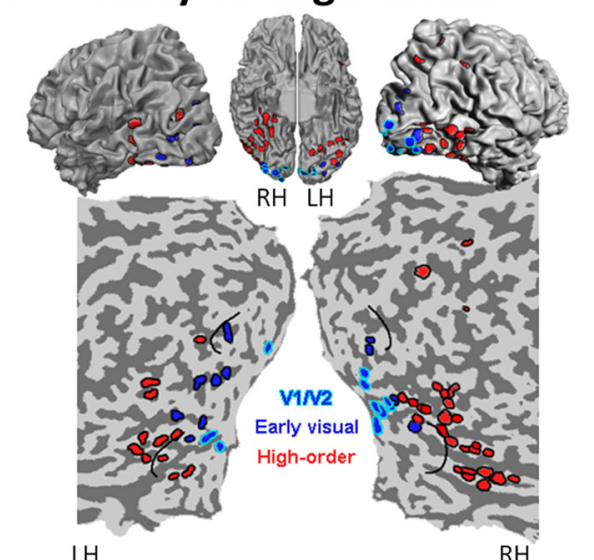

B Spatial selectivity

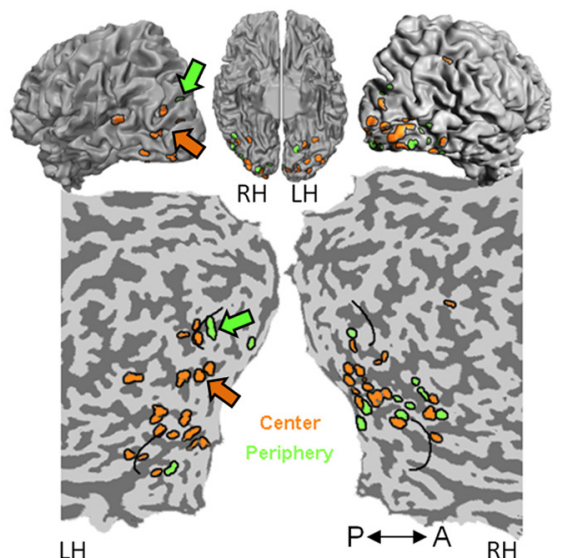

$\mathrm{D}$
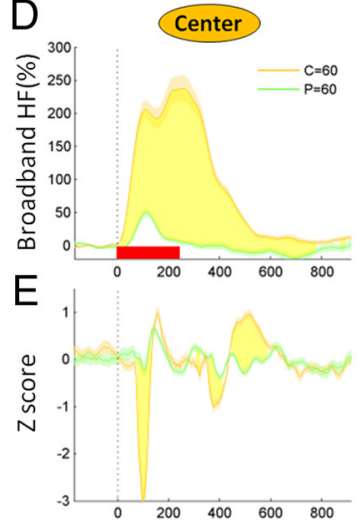
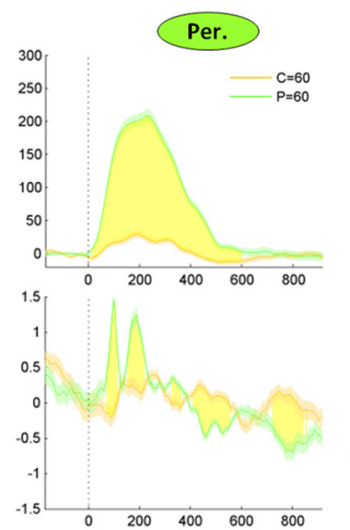

Time (ms)

C Object selectivity

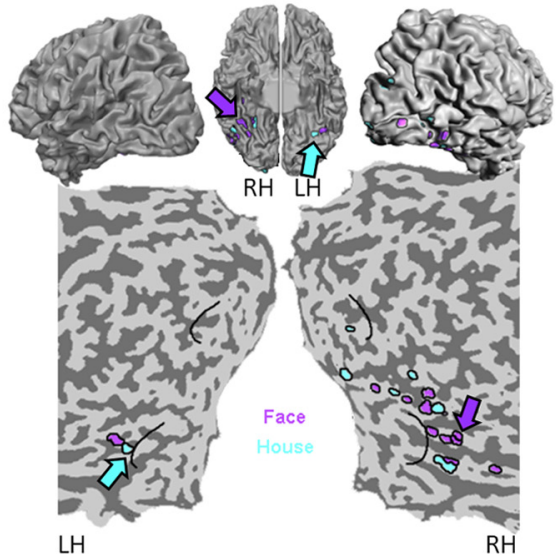

$\mathrm{F}$
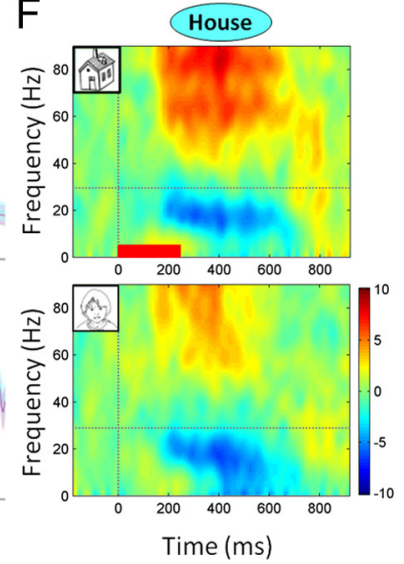

Figure2. Distribution of visually responsive electrodes and typical response profiles. A, Classification of visual electrodes as V1/V2 (blue with a cyan contour), early (blue) or high-order (red). The electrodes were superimposed on a cortical reconstruction of a healthy subject from a previous fMRI study. Electrode positions are shown on a ventral view of the cortical hemispheres (middle top row), on a lateral view of the cortical hemispheres (top row, right and left), and on an unfolded occipitotemporal cortical surface (bottom). Estimated borders of early visual cortex based on a previous fMRI study are shown in black on the unfolded cortical surface. $B$, Spatial selectivity map: visual electrodes that showed a significant $(p<0.05$, uncorrected) preference to the center (orange) or to the periphery (green) of the visual field in the stimulus control experiment. P, Posterior; A, anterior. C, Object selectivity map: visual electrodes that showed a significant ( $p<0.05$, uncorrected) preference to faces (purple) or houses (cyan). D, From left to right: broadband HF $(30-90 \mathrm{~Hz})$ responses from the stimulus control experiment of 2 early visual electrodes (center- and peripheryselective) and of 2 high-order visual electrodes (face-and house-selective). $\boldsymbol{B}, \boldsymbol{C}$, The locations of these four electrodes are marked by arrows of the corresponding colors. SEM is given by shading, and time points showing a significant difference between the two conditions ( $p<0.05$, corrected) are shown in yellow. Stimulus onset is marked by a dashed vertical line, and the red horizontal bar (left panel) indicates image presentation duration. Note the robust spatial and object selectivity manifested by the broadband HF responses. $\boldsymbol{E}$, VEPs of the four electrodes shown in $\boldsymbol{D}$. The number of trials refers to both $\boldsymbol{D}$ and $\boldsymbol{E}$. $\boldsymbol{F}$, Time-frequency decompositions of a representative visual electrode (house-selective in this example). The spectrograms show the induced spectral responses to houses (top) and faces (bottom). The spectrogram's colors indicate power increase (red) or decrease (blue) relative to prestimulus baseline. The dashed vertical line indicates stimulus onset, and the dashed horizontal line indicates the lower bound $(30 \mathrm{~Hz}$ ) of the broadband $\mathrm{HF}$ response. C, Center; $\mathrm{P}$, periphery; $\mathrm{F}$, face; $\mathrm{H}$, house.

The magnitude of the spatial attention modulation (see Fig. 4) was defined as the absolute value of the spatial attention index. We also computed the effective attention index (see Fig. 7) as follows:

$$
\text { EAI }=\frac{\text { mean }(\text { abs_spatial_attention_idx, abs_object_attention_idx })}{\text { mean }(\text { abs_spatial_selectivity_idx, abs_object_selectivity_idx })}
$$

Population analysis. In the population analysis of spatial attention effects in early visual cortex (see Fig. 4E), we computed the averaged broadband HF responses across all early visual electrodes, separately for the "preferred location attended" versus "nonpreferred location attended" conditions. The responses were normalized by the peak of the broadband HF response to the "preferred location attended."

A similar analysis was performed in Figure 6 (top row) for high-order visual electrodes. Here we differentiated between 2 sets of high-order visual electrodes based on their selectivity in the stimulus control experiment: spatial selective electrodes (left) and object selective electrodes (right). For object-selective electrodes, the comparison was between "preferred object attended" and "nonpreferred object attended." Note that this differentiation between spatial and object selective electrodes was not feasible for early visual electrodes because of the small number of early visual electrodes that showed object selectivity $(n=3)$.

In the VEP analysis (see Fig. 8), the electrode sets were defined based on the VEPs in the stimulus control experiment. Then, the VEPs in the attention experiment were averaged within each electrode set according to the preferred location or object. VEPs were plotted as $z$-scores and not as voltages because the absolute voltage values were highly variable across electrodes. A major part of this variance probably stemmed from the specific position of the electrode relative to the surface of the cortex. Therefore, the VEPs were $z$-scored and only then averaged across electrodes.

\section{Statistical tests}

Statistical significance of stimulus modulation (i.e., spatial and object selectivity) of each recording electrode was determined by means of a two-way ANOVA with factors eccentricity (center or periphery) and object category (face or house). The two-way ANOVA was performed on the broadband HF responses AUC in a time window of 50-600 ms after stimulus onset. These responses were acquired during the stimulus control experiment. Because the stimulus modulation was used only as a 
Table 2. Reaction times, accuracy rates, and false alarm rates for the different attentional conditions

\begin{tabular}{|c|c|c|c|c|c|c|}
\hline & Attend center & Attend periphery & Attend face & Attend house & $F(\mathrm{df})$ & $p$ value \\
\hline \multicolumn{7}{|l|}{ Spatial attention } \\
\hline $\mathrm{RT}$ (ms) & $639.9 \pm 27.6$ & $624.5 \pm 21.5$ & & & $0.98_{(1,8)}$ & 0.35 \\
\hline Accuracy (\%) & $85.3 \pm 2.7$ & $77.3 \pm 4.2$ & & & $4.96_{(1,8)}$ & 0.06 \\
\hline False alarms (\%) & $4.3 \pm 1.7$ & $3.4 \pm 1.2$ & & & $0.19_{(1,8)}$ & 0.67 \\
\hline \multicolumn{7}{|l|}{ Object-based attention } \\
\hline $\mathrm{RT}(\mathrm{ms})$ & & & $628.4 \pm 28.2$ & $649.3 \pm 24.2$ & $1.99_{(1,8)}$ & 0.19 \\
\hline Accuracy (\%) & & & $84.2 \pm 3.3$ & $78.5 \pm 3.9$ & $1.97_{(1,8)}$ & 0.20 \\
\hline False alarms (\%) & & & $4.3 \pm 1.4$ & $3.3 \pm 1.0$ & $0.78_{(1,8)}$ & 0.40 \\
\hline
\end{tabular}

Data are mean \pm SEM across subjects.

localizer, i.e., to select electrodes for the main attentional modulation analysis, no correction for multiple comparisons was used.

Statistical significance of attentional modulation in electrodes that were either spatial or object-selective was determined by two methods: (1) A two-way ANOVA with factors eccentricity (attend center or periphery) and object category (attend face or house). The two-way ANOVA was performed on the broadband HF responses AUC on a time window of 50-600 ms after stimulus onset acquired during the attention experiment. (2) A point-by-point paired $t$ test on a time window of 50-1000 ms post-stimulus onset comparing the broadband HF responses when the preferred eccentricity/category was attended and the response when the nonpreferred eccentricity/category (respectively) was attended. Multiple comparisons were corrected using the false discovery rate (FDR) procedure (Benjamini and Hochberg, 1995).

This point-by-point $t$ test and multiple comparisons correction was used also to mark time points with a significant difference between any 2 conditions (marked as a yellow area throughout the figures).

To compute the response latency and the attentional modulation latency of each visual electrode (see Fig. 4B), the Student's $t$ test was used for each individual time point (FDR corrected). The response latency was defined as the time point in which broadband HF power first became significantly greater than its prestimulus baseline value (Fisch et al., 2009). Attentional modulation latency was defined as the time point in which the broadband HF power in attending the preferred location/ category first became significantly greater than the broadband HF power in attending the nonpreferred location/category (respectively).

In the population analyses (see Figs. 6,8 ), given the relatively small sample sizes, the significance of the attentional effects was assessed using the paired Wilcoxon signed rank test.

All tests were one-sided and in all of them Alpha was set as 0.05.

\section{Results}

Ten patients ( 2 males, 9 right-handed, age: $30 \pm 3.9$ (mean \pm SEM; Table 1), implanted with intracranial electrodes for presurgical evaluation, participated in the present study. The patients performed two experiments (Fig. 1). In the attention experiment, the patients were presented with composite stimuli, consisting of a small object (line drawing of either a face or a house) superimposed on a large one. In separate blocks, the patients were cued to detect a specific target at the center or at the periphery while maintaining fixation (see Materials and Methods). Note that, because the images were concentric, the large image size was associated with peripheral eccentricities whereas the small image size was associated with central ones. In the rest of this manuscript, we refer to the large versus small sizes as "spatial" modulations, bearing in mind that in the present experiment we could not dissociate size and eccentricity aspects.

The same composite images appeared in both attention conditions in different orders; thus, the retinal input at various attentional conditions was identical. Importantly, this paradigm allowed manipulating not only spatial attention but also objectbased attention. Because the object categories were always mixed (e.g., a face within a house) and because they were held constant at each eccentricity within a given block, attending a certain eccentricity (center vs periphery) inevitably also meant attending a certain object category. However, the counterbalance of object categories and eccentricities allowed a $2 \times 2$ design isolating the eccentricity and object category effects. In the second experiment ("stimulus control experiment"; Fig. 1B), only one object was presented (small or large, face or house) to assess the spatial and object selectivity of each recording electrode.

Analysis of the behavioral data showed that the patients performed the attentional task at a high level of accuracy (81.2 \pm $3.0 \%)$ and a low rate of false alarms $(3.8 \pm 1.0 \%)$, indicating that they managed to allocate attention to the cued eccentricity and object category. Importantly, a two-way repeated-measures ANOVA with factors eccentricity (attend center or periphery) and object category (attend face or house) showed that there were no significant differences between the attentional conditions both in accuracy rates and in reaction times (Table 2). Figure $2 \mathrm{~A}$ depicts the distribution of all the visually responsive electrodes $(n=65)$ from the entire patient population (see Materials and Methods for statistical criteria), projected on a cortical reconstruction of a healthy subject from a previous fMRI study. Despite the fact that coverage of visual areas, and specifically, early visual areas, is rare in these patients, over an extended period of time (2 years) we managed to accumulate recording sites spanning the entire visual hierarchy, from V1 up to the fusiform gyrus. A time-frequency decomposition of a representative visual electrode is presented in Figure $2 F$. Inspection of the spectral decomposition shows a typical broadband-positive response $(>30 \mathrm{~Hz})$ coupled with a reduction in low frequencies $(5-25 \mathrm{~Hz})$ power (also termed event-related desynchronization) (Crone et al., 2006; Privman et al., 2011). Therefore, our analysis focused on broadband HF $(30-90 \mathrm{~Hz})$ changes in the spectral power of the ECoG signals. Unless mentioned otherwise, we focused on a time window of 50-600 ms after stimulus onset, which was chosen in accordance with the duration of the broadband HF response in both early and high-order visual areas (Fig. 2D) and with the long latencies of attentional effects in V1/V2 reported in previous studies (Buffalo et al., 2010).

The visually responsive electrodes were divided into early and high-order visual electrodes based on two criteria: (1) geodesic distance (i.e., distance along the cortical surface): electrodes located $40 \mathrm{~mm}$ or less from the occipital pole (Murphey et al., 2009) and which showed (2) response latency of $100 \mathrm{~ms}$ or less (Fisch et al., 2009) were defined as early visual. Following Yoshor et al. (2007), a subset of early visual electrodes were assigned to V1/V2 based on their anatomical locations (see Materials and Methods). As can be seen in Figure 2A, 22 electrodes in 5 of the patients were identified as early visual electrodes (blue), of which 10 electrodes were assigned to V1/V2 (blue with a cyan contour), and 40 electrodes in 7 of the patients were classified as high-order visual 

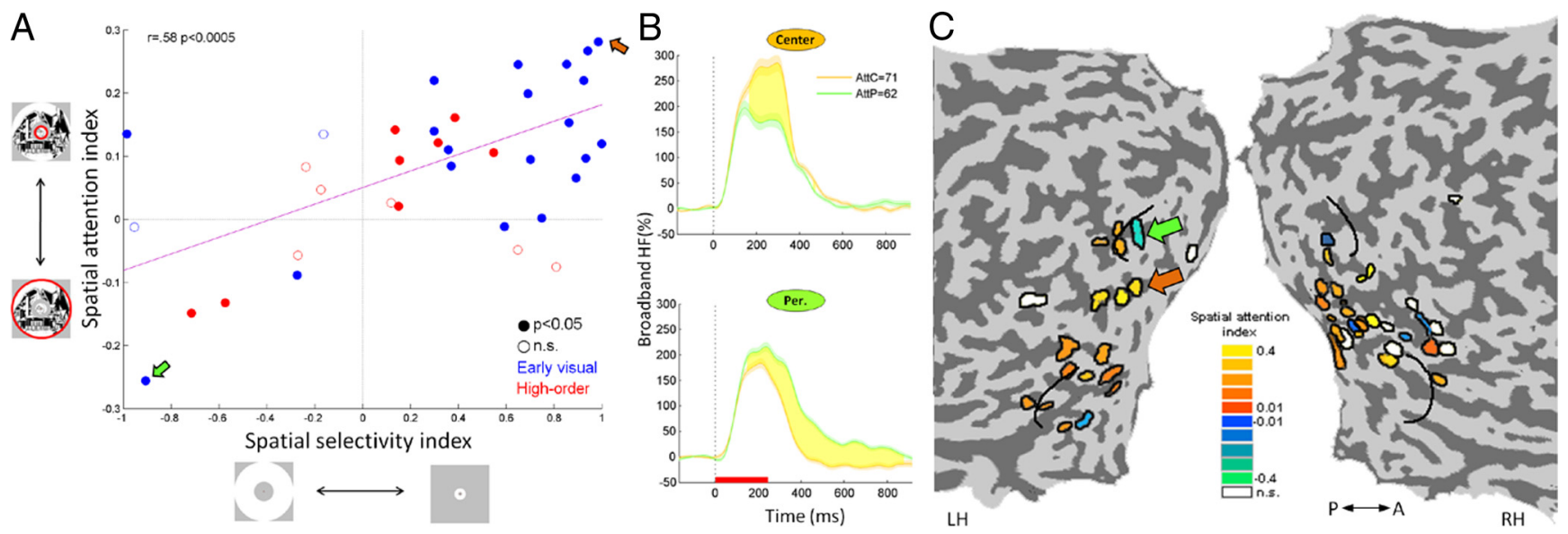

Figure 3. Spatial attention effects along the visual cortical hierarchy. $A$, Correlation between spatial attention index ( $y$-axis, assessed in the attention experiment) and spatial selectivity index $(x$-axis, assessed in the stimulus control experiment) in early (blue) and high-order (red) electrodes. Positive attentional modulation values indicate an enhanced visual response when the central image was attended, and negative values indicate an enhanced response when the peripheral image was attended. Positive spatial selectivity values indicate preference to the center of the visual field, and negative values indicate preference to the periphery. Filled dots indicate electrodes that exhibited a significant difference $(p<0.05$, FDR corrected) between the broadband HF responses when the central versus peripheral image was attended. Note the tight positive relationship between stimulus selectivity and attentional effects, indicating that attention produced an enhancement in broadband HF response when corresponding to the preferred location. $\boldsymbol{B}$, Spatial attention modulation of broadband HF responses in two early visual electrodes: one selective to the center of the visual field (top) and the other to the periphery (bottom). A, C, Each electrode is marked by an arrow of the corresponding color. Its stimulus preferences are shown in Figure $2 D$. AttP, Attend periphery; AttC, attend center. The conventions are the same as in Figure 2D. C, Locations of all the spatial selective electrodes presented in $\boldsymbol{A}$, projected on an unfolded occipitotemporal cortical surface. The electrodes are color-coded according to the sign and magnitude of the spatial attention index.

electrodes (red). Three visual electrodes were located in close proximity to the occipital pole $(<40 \mathrm{~mm})$ but showed long latency responses $(>100 \mathrm{~ms}$ ) and were thus excluded from further analysis. Next, we examined the extent to which each electrode showed spatial selectivity (i.e., preferential response to the center or to the periphery of the visual field: small and large images, respectively, regardless of the object category) and object selectivity (i.e., preferential response to faces or houses, regardless of their eccentricity). Both measures were derived from the stimulus control experiment. All 22 early visual electrodes exhibited significant spatial selectivity ( $p<0.05$, uncorrected, two-way ANOVA; see Materials and Methods), further validating their classification as early visual electrodes. The majority of the early visual electrodes showed preference to the center of the visual field (17 of 22; Fig. 2B). Three early visual electrodes also showed significant object selectivity with two preferring the house category and one preferring the face category. Of the 40 high-order visual electrodes, 15 electrodes were space/size-selective and 16 were object selective (Fig. $2 \mathrm{~B}, \mathrm{C}$ ). An example broadband $\mathrm{HF}$ and visual evoked responses of 2 early and 2 high-order visual electrodes are shown in Figure 2, $D$ and $E$.

\section{Spatial attention effects in early visual cortex}

First, we examined the extent to which responses in early visual cortex were modulated by spatial attention. For each electrode, a two-way ANOVA with factors eccentricity (attend center or periphery) and object category (attend face or house) was performed based on the broadband HF area AUC in a time window of 50-600 ms after stimulus onset. Sixteen of the 22 early visual cortex electrodes $(73 \%)$ showed a significant $(p<0.05$, uncorrected) main effect of eccentricity-based attention. Figure $4 E$ depicts the grand-averaged broadband HF responses of all early visual electrodes when the preferred location was attended (orange) and when it was ignored (green). As can be seen, at the group level early visual electrodes showed a highly significant effect of spatial attention (attend preferred location AUC: $0.59 \pm$
0.01 , attend nonpreferred location AUC: $0.48 \pm 0.01, p<0.0005$, Wilcoxon signed rank test).

Second, we asked whether the spatial attention modulation reflects the spatial selectivity (i.e., preference to the center or to the periphery of the visual field) of each electrode. To that aim, two indices were computed for each electrode based on the AUC of the broadband HF response: a spatial selectivity index, which measured the preference of the electrode to the center or to the periphery of the visual field based on the stimulus control experiment, and a spatial attention index, which quantified the modulation of the visual response by spatial attention in the main experiment. These indices were also computed as $\mathrm{d}^{\prime}$ values (see Materials and Methods). This analysis was performed on all visual electrodes (both early visual and high order) that showed spatial selectivity in the stimulus control experiment. Note that only 3 electrodes ( $4.6 \%$ of the visual electrodes) exhibited a significant spatial attention modulation despite not showing spatial selectivity. We found a significant correlation between these two indices $(r=0.58, p<0.0005)$ : electrodes that were tuned to the center of the visual field showed enhanced broadband HF visual responses when the patient attended the central image, and vice versa for peripheral electrodes. Furthermore, electrodes showing narrower tuning to spatial location also showed stronger spatial attention modulation (Fig. $3 A, B$ ). This correlation was also obtained using the spatial selectivity $\mathrm{d}^{\prime}$ and spatial attention $\mathrm{d}^{\prime}(r=$ $\left.0.67, p<10^{-5}\right)$.

Next, we examined to what extent the magnitude of the attentional modulation depended on the level of visual hierarchy. Because fMRI retinotopic mappings were not feasible in this patient's cohort, we measured the geodesic distance of each electrode from the occipital pole (OP) as an indirect anatomical index of cortical hierarchy (Murphey et al., 2009). Over the entire visual electrodes population, this measure was significantly correlated to the response latency of each electrode $(r=0.56, p<$ $10^{-5}$ ), supporting its use as an approximate proxy of visual hierarchy. The magnitude of the attentional modulation was defined 
A

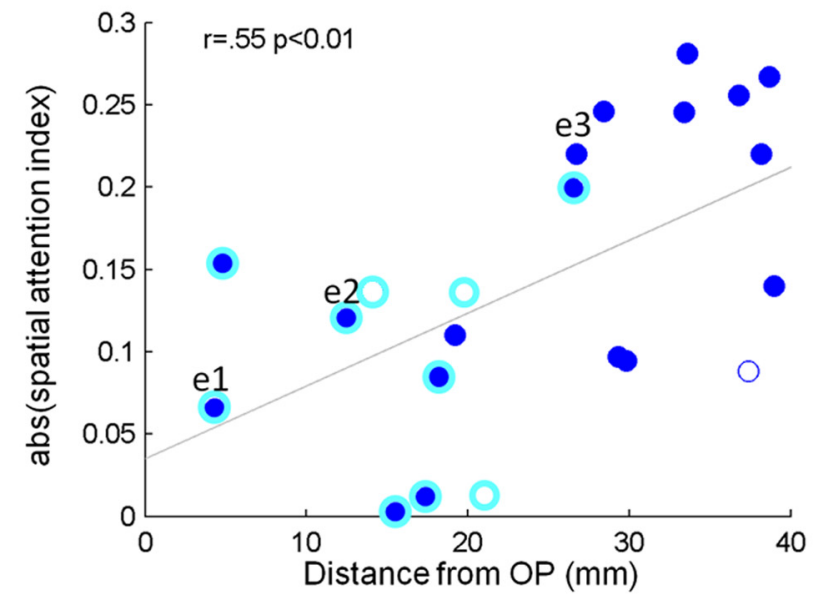

B

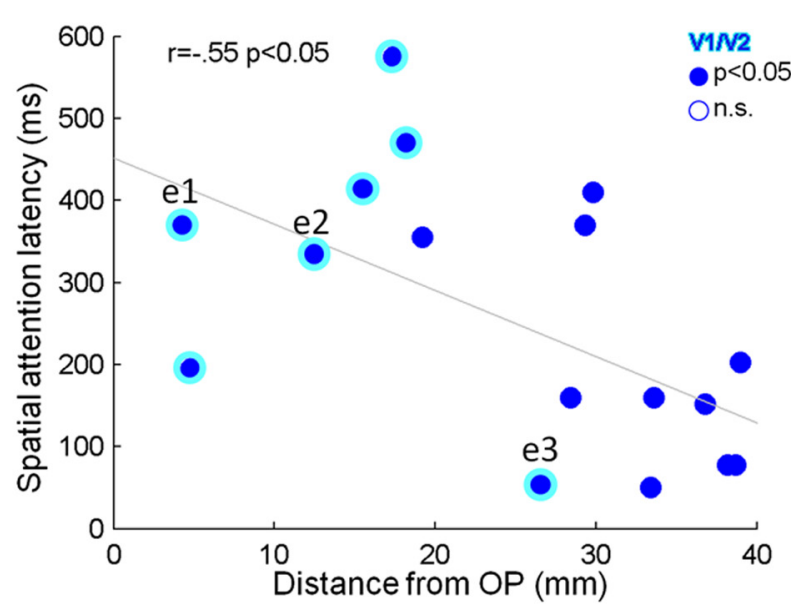

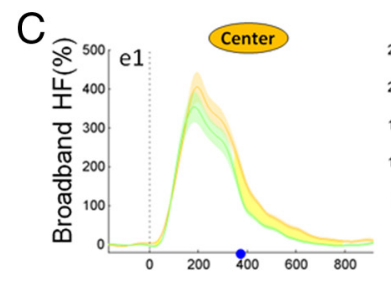
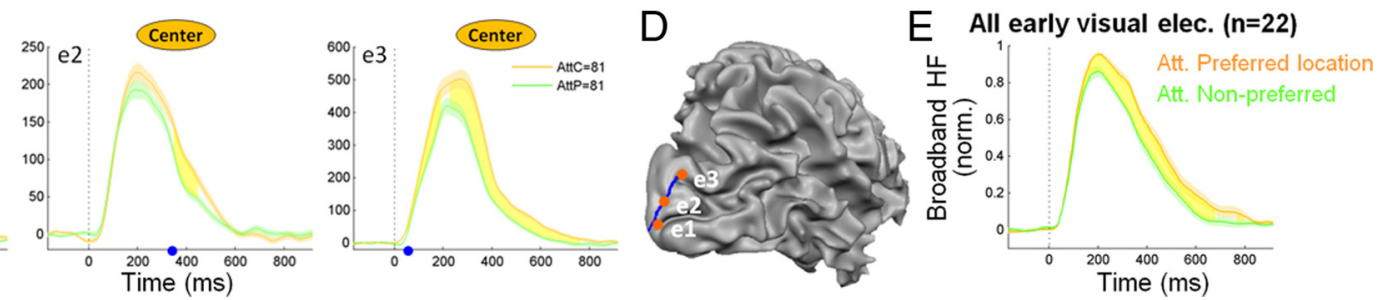

Figure 4. Spatial attention effects in early visual cortex: magnitude and latency. $A$, Correlation between the magnitude of spatial attention modulation (absolute value of the spatial attention index) and geodesic distance (i.e., distance along the cortical surface) from the OP in early visual electrodes. V1/V2 electrodes are marked by a cyan contour. $\boldsymbol{B}$, Correlation between the latency of the attentional modulation, defined as the first time point in which the two attentional conditions showed a significant difference, and geodesic distance from the $0 P$. C, $D$, Broadband $H F$ responses of three adjacent early visual electrodes located at increasing distances from the OP (from left to right) and recorded simultaneously in the same patient during the attention experiment. The attentional modulation latency is marked by a blue dot on the $x$-axis. The electrodes are marked as "e1," "e2," and "e3" in all panels, and their locations are shown on a cortical reconstruction of the right hemisphere along with the geodesic distance from the OP (blue path) (D). Note that as the geodesic distance (reflecting indirectly the level of cortical hierarchy) increases, the latency of attentional modulation decreases, suggesting a sequential wave of attentional modulation moving from high to low visual regions. $E$, Grand-averaged broadband $\mathrm{HF}$ responses of all early visual electrodes ( $n=22)$ when the preferred location was attended (orange) compared with when it was ignored (green).

as the absolute value of the spatial attention index (see Materials and Methods). Within early visual cortex, there was a significant correlation between the magnitude of spatial attention modulation and the distance from the occipital pole $(r=0.55, p<0.01$; using $\mathrm{d}^{\prime}$ values: $\left.r=0.66, p<0.001\right)$ : attentional modulation became larger at more anterior visual areas (Fig. 4A). However, this effect could not be the result of more selective spatial tuning because the correlation between spatial selectivity and distance from the occipital pole within early visual cortex was not significant $(r=-0.22, p=0.31)$.

An interesting issue concerns the timing of the attentional effect with increasing distances from the occipital pole (i.e., higher approximate hierarchy). To examine this phenomenon, we computed the latency of the attentional modulation of each electrode. For this analysis, a longer time window was considered (up to $1 \mathrm{~s}$ after stimulus) and the significance of the attentional modulation was assessed for each time point individually $(p<$ 0.05 ; FDR corrected; see Materials and Methods). Using this criterion, $81 \%$ of the early visual electrodes in general and $70 \%$ of the V1/V2 electrodes in particular exhibited significant attentional modulation, indicating that this time window was more sensitive to attentional effects. Moreover, this analysis revealed that the latency of the attentional modulation was negatively correlated with the distance from the occipital pole: attentional modulation appeared earlier in time in anterior relative to posterior early visual electrodes $(r=-0.55, p<0.05$; Fig. $4 B)$. This effect could not be attributed to differences in response latency because the correlation between attentional latency and response latency was not significant $(r=0.38, p=0.11)$. Moreover, for each early visual electrode, we computed the difference between the response latency and the attentional modulation latency ("attentional lag"). The attentional lag ranged from $0 \mathrm{~ms}$ (i.e., attentional modulation present at the onset of the visual response) to $485 \mathrm{~ms}$. Like the latency of the attentional modulation itself, the attentional lag was negatively correlated with the distance from the occipital pole $(r=-0.53, p<0.05)$, further supporting the notion that the latency of the attentional modulation was reduced at longer distances from the OP.

Figure $4 C$ depicts examples of three adjacent early visual electrodes recorded simultaneously from the same patient (their anatomical locations are shown in Fig. 4D). As can be seen, the more anterior electrode exhibited stronger attentional modulation, which occurred earlier in time $(370 \mathrm{~ms}$ in the most posterior electrode vs $50 \mathrm{~ms}$ in the most anterior electrode). Could the early onset of the attentional effect be a mere confound of the magnitude of the attentional effect? Are the shorter attentional latencies in anterior sites simply because of the better signal-to-noise ratio of the attentional modulation? To address this issue, we computed for each early visual electrode the signal-to-noise ratio of the attentional modulation (mean/variance across trials). There was no significant correlation between this signal-to-noise ratio measure and the distance from the OP $(r=-0.34, p=0.12)$, or with the attentional latency $(r=0.13, p=0.60)$, rendering this explanation unlikely. 

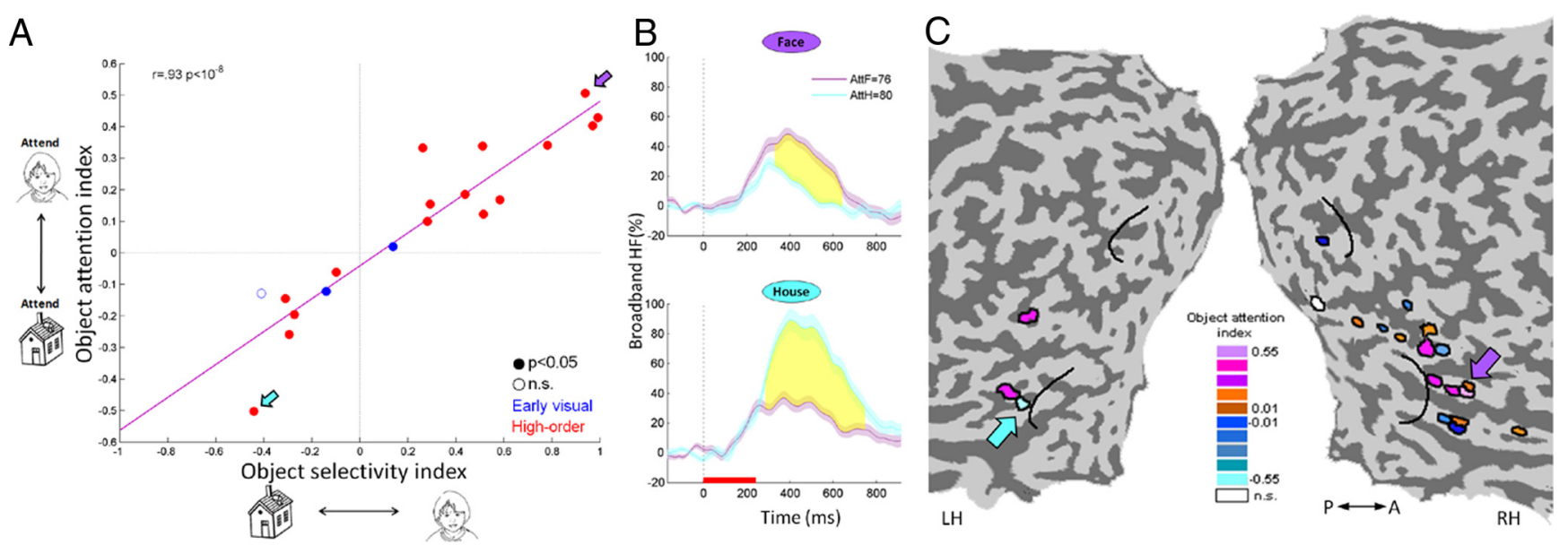

Figure 5. Object-based attention effects along the visual cortical hierarchy. $A$, Correlation between object-based attention index ( $y$-axis, assessed in the attention experiment) and object selectivity index ( $x$-axis, assessed in the stimulus control experiment) in early (blue) and high-order (red) electrodes. Positive attentional modulation values indicate an enhanced visual response when faces were attended, and negative values indicate an enhanced response when houses were attended. Positive object selectivity values indicate preference to faces, and negative values indicate preference to houses. $\boldsymbol{B}, 0$ bject-based attention modulation of the broadband HF responses in two high-order visual electrodes: one selective to faces (top) and the other to houses (bottom). $A, C$, Each electrode is marked by an arrow of the corresponding color. Its stimulus preferences are shown in Figure 2D. AttF, Attend faces; AttH, attend houses. $C$, Locations of all the object selective electrodes presented in $A$, projected on an unfolded occipitotemporal cortical surface. The electrodes are color-coded according to the sign and magnitude of the object-based attention index. The conventions are the same as in Figure 3.

\section{Object-based attentional effects in high-order visual cortex}

Within each block of the attention experiment, a certain eccentricity was always coupled with a certain object category. Therefore, even though the patients were explicitly instructed to attend a certain eccentricity, they also attended a certain object category. Sixteen high-order visual electrodes were object-selective and $88 \%$ of them (14 of 16) showed a significant main effect of objectbased attention $(p<0.05$, uncorrected, two-way ANOVA; see Materials and Methods). Note that only 3 electrodes ( $4.6 \%$ of the visual electrodes) exhibited a significant object-based attention modulation despite not showing object selectivity; therefore, the following analysis was limited to object selective electrodes only (Moran and Desimone, 1985; Reynolds et al., 2000; Maunsell and Treue, 2006).

In a similar manner to the spatial domain, two indices were calculated for each electrode: an object selectivity index, which captured the preference of each electrode to faces or houses in the stimulus control experiment, regardless of their eccentricity, and an object-based attention index, which quantified the modulation of the visual responses by attending a certain object category, regardless of eccentricity. As can be seen in Figure 5, $A$ and $B$, throughout the visual hierarchy there was a striking coupling between the object selectivity of each electrode and its modulation by object-based attention $\left(r=0.93, p<10^{-8}\right.$; using $\mathrm{d}^{\prime}$ values: $r=0.94, p<10^{-8}$ ): electrodes that were face-selective showed enhanced broadband HF power when the patient attended faces, and vice versa for house-selective electrodes. The sharper the object selectivity became, the stronger the attentional modulation. The mean object-based attentional modulation latency in object-selective electrodes was $254 \pm 26 \mathrm{~ms}$, and it lagged the response latency by $142 \pm 23 \mathrm{~ms}$.

\section{Spatial attention effects in high-order visual cortex}

To what extent did high-order visual areas also exhibit spatial/ size attention modulation, regardless of object-based attention? Inspection of the anatomical distribution of spatial selective electrodes (Fig. 3C) revealed that spatial attention effects were not confined to early visual electrodes. Rather, spatial attention modulations were present throughout the entire visual hierarchy. To quantify this effect, we selected high-order visual electrodes, which showed a significant spatial preference in the stimulus control experiment, and examined whether they manifested spatial attention effects as well. For each attentional condition (i.e., attend preferred location vs attend nonpreferred location), we computed the broadband HF response, averaged across all the electrodes in the set. Note that the electrodes in this analysis were selected not only according to their anatomical location (highorder visual cortex) but also according to their stimulus preferences. This analysis was performed also in the object domain for comparison.

Were there any high-order visual cortex sites that showed size or eccentricity selectivity and did they exhibit attentional modulation as well? As can be seen in Figure 6A (top row), high-order visual electrodes that were spatially selective $(n=15)$ also exhibited a significant spatial attention modulation: the AUC in the "attend preferred location" condition was $0.24 \pm 0.01$, whereas the AUC in the "attend nonpreferred location" was $0.21 \pm 0.01$ $(p<0.005$, paired Wilcoxon signed rank test; see Materials and Methods). As expected, high-order visual electrodes that were object selective $(n=16)$ showed a highly significant object-based attentional modulation (Fig. 6B, top row): the AUC in the "attend preferred object" condition was $0.25 \pm 0.01$, whereas the AUC in the "attend nonpreferred object" was $0.16 \pm 0.01(p<$ 0.0005 , paired Wilcoxon signed rank test).

Next, we selected a subset of 7 face-selective electrodes located ventrally along the fusiform gyrus (with the exception of two electrodes placed over the inferior temporal gyrus; Fig. 2C). Note that these electrodes were selected based on their object selectivity and anatomical locations; nonetheless, they exhibited a significant spatial attention modulation, with the majority showing a central visual field preference (attend center AUC: $0.23 \pm 0.02$, attend periphery AUC: $0.20 \pm 0.02, p<0.05$, paired Wilcoxon signed rank test; Fig. $6 A$, bottom row).

It is important to note that in early visual electrodes we did not find any significant modulation of the baseline broadband HF activity (Fig. $4 E$ ). In object-selective high-order visual electrodes, a point-by-point comparison revealed a slight trend $(p<0.05$, uncorrected) of elevated prestimulus activity when the preferred 
A

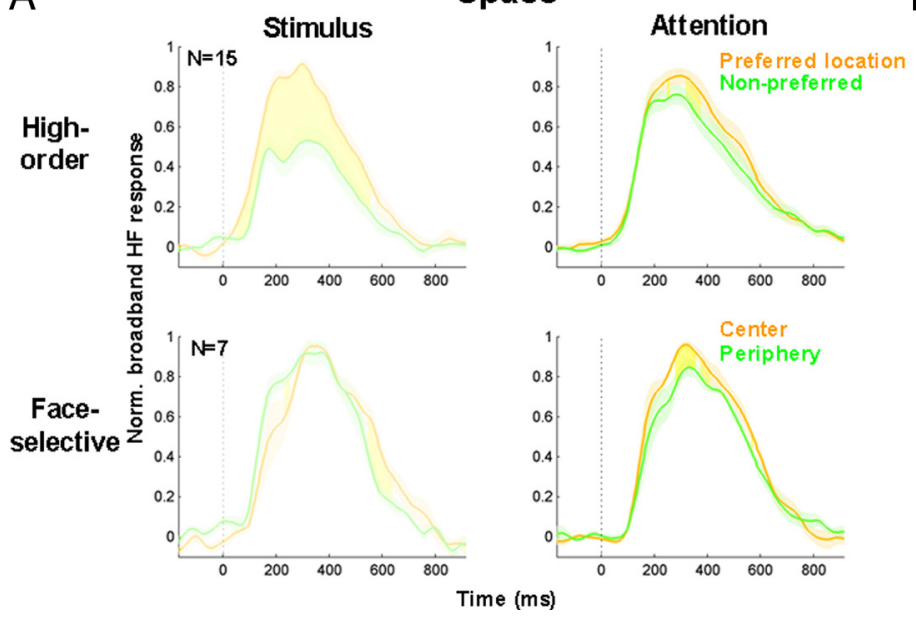

B

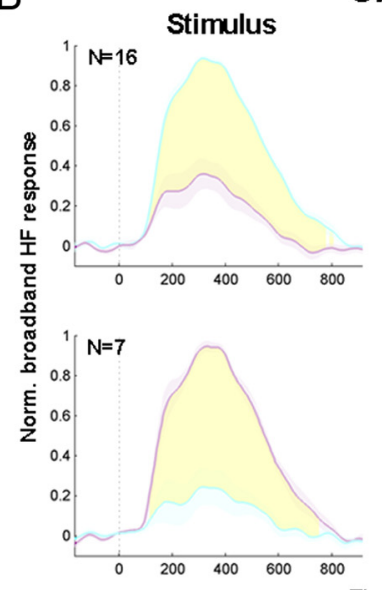

Object
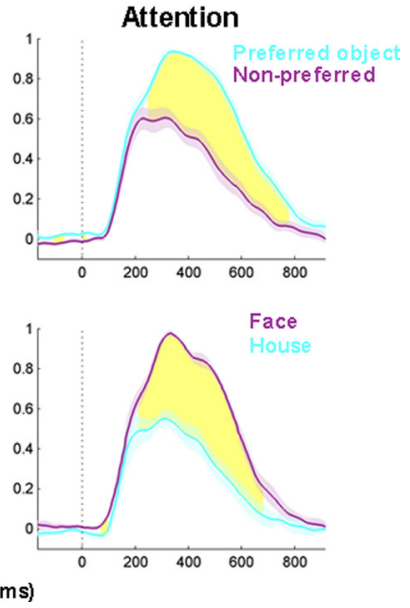

Figure 6. Grand-averaged attentional modulations of broadband HF responses in high-order visual cortex. $A$, Spatial attention effects. Top row left, Grand-averaged broadband HF responses of 15 spatial selective high-order visual electrodes to the preferred (light orange) and nonpreferred (light green) locations. Top row right, Broadband HF responses of these electrodes when the preferred location was attended (orange) and when it was ignored (green). Bottom row, Same as above for 7 face-selective electrodes located ventrally along the fusiform gyrus. Note that the comparison in this panel is between "attend center" (orange) and "attend periphery" (green). B, Object-based attention effects. Top row left, Grand-averaged broadband HF responses of 16 object-selective high-order visual electrodes to the preferred (cyan) and nonpreferred (purple) objects. Top row right, Broadband HF responses of these electrodes when the preferred object was attended (cyan) and when it was ignored (purple). Bottom row, Same as above for 7 ventral face-selective electrodes. The comparison in this panel is between "attend face" (purple) and "attend house" (cyan). SEM (across electrodes) is given by shading, and time points showing a significant difference between the two conditions ( $p<0.05$, uncorrected) are shown in yellow.

object was attended compared with when it was ignored (Fig. 6B, right top).

\section{Effective attentional modulation}

To what extent does the attentional modulation reflect the sign and magnitude of stimulus modulation in a given area? A total of $82 \%$ of the spatial selective electrodes and $100 \%$ of the object selective electrodes showed an attentional modulation that was of the same sign as the stimulus selectivity (i.e., attention increased the broadband HF responses in accordance with the stimulus preference of the recording sites; see Figs. 3, 5). To compare the magnitudes of the attentional and stimulus modulations we computed, for each spatial or object selective electrode, an effective attention index (EAI). The EAI was defined as the ratio between the mean attentional modulation (eccentricity and object-based) and the mean stimulus modulation, thus representing a global attention modulation index (see Materials and Methods). There was a significant correlation between the EAI and the distance from the occipital pole $(r=0.49, p<0.0005$; Fig. $7 B)$. In early visual electrodes, the attentional modulation was $27 \pm 4 \%$ of the stimulus modulation, whereas in high-order electrodes this ratio reached a level of $50 \pm 4 \%$. The EAI was also correlated to the response latency of each electrode $(r=0.56, p<0.0005$; Fig. $7 A$ ), thus further validating the enhancement of effective attentional modulation along the visual hierarchy (Fig. $7 C$ ).

\section{Attentional modulation of VEPs}

Up to this point, we focused on attentional modulation of the broadband HF responses. However, as can be seen in Figure 2E, spatial and object preferences were evident also in the VEPs. Are the VEPs also modulated by attention? To examine this point, we selected a subset of early visual electrodes that showed a significant spatial selectivity in the VEPs acquired during the stimulus control experiment $(n=15)$. Then, we compared the VEPs acquired during the attention experiment when the preferred location was attended versus when it was ignored. As can be seen in Figure $8 A$, despite the robust spatial selectivity (top row, left), the
$A_{\text {등 }}$
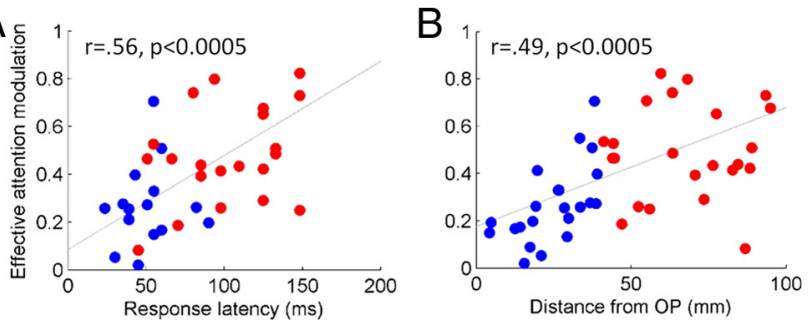

C
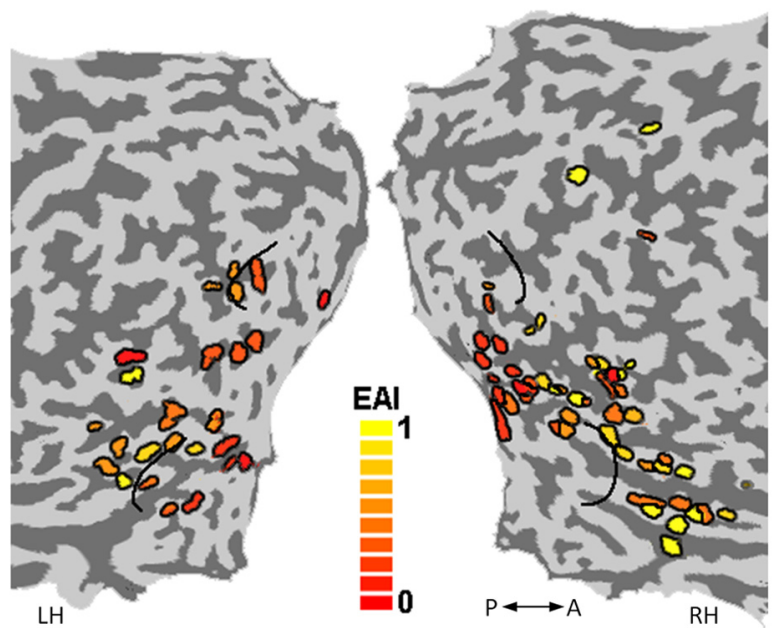

Figure 7. Effective attention modulation along the visual hierarchy. $A$, Correlation between the effective attention modulation (attentional modulation divided by stimulus modulation; $y$-axis) and response latency ( $x$-axis). $B$, Correlation between the effective attention modulation ( $y$-axis) and distance from the OP ( $x$-axis). $C$, Visualization of the effective attention modulation of all visual electrodes projected on a flattened cortical surface. Note the clear progression of the effective modulation with geodesic distance and latency, suggesting an increased impact of attentional modulation along the cortical hierarchy.

VEPs failed to exhibit any attentional modulation (top row, right). As for the broadband HF responses, we computed the AUC of the VEPs in a time window of 50-600 ms after stimulus onset (see Materials and Methods). There was no significant dif- 
A

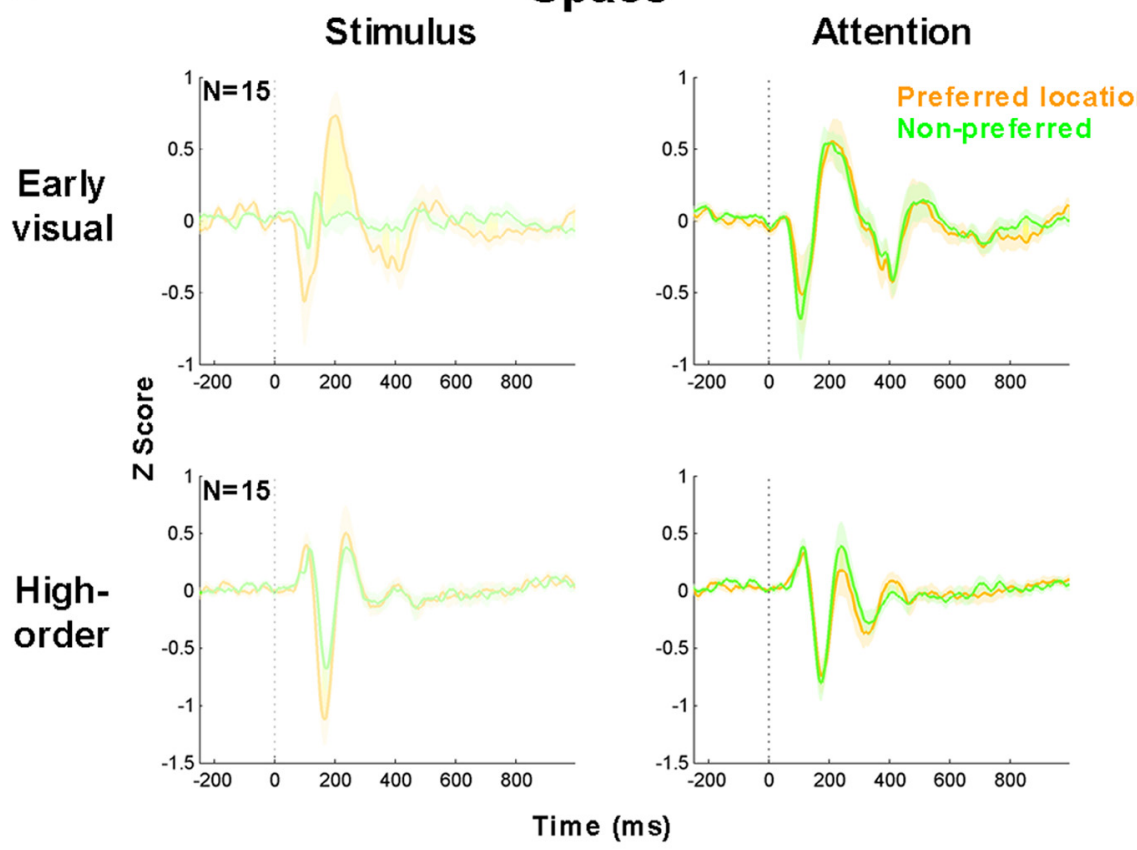

B

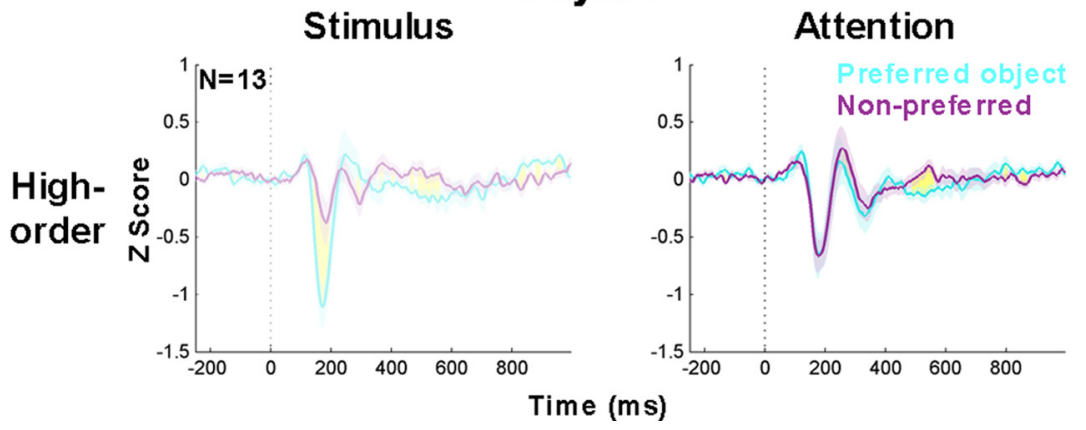

Figure 8. Lack of attentional modulation of the VEPs. A, Spatial attention effects. Top row, Grand-averaged VEPs of 15 spatial selective early visual electrodes. Bottom row, Grand-averaged VEPs of 15 spatial selective high-order visual electrodes. $\boldsymbol{B}$, Objectbased attention effects. Grand-averaged VEPs of 14 object-selective high-order visual electrodes. Note that, despite the robust stimulus selectivity (left), the VEPs failed to reveal a significant attentional modulation (right). The format and conventions are the same as in Figure 6.

ference between the AUC estimates of the two attentional conditions (attend preferred location AUC: $0.26 \pm 0.02$, attend nonpreferred location AUC: $0.24 \pm 0.02, p=0.33$, paired Wilcoxon signed rank test). A similar result was obtained in a subset of 13 high-order visual electrodes, which showed clear object selectivity (Fig. $8 B$ ) but failed to exhibit significant attentional modulation (attend preferred object AUC: $0.22 \pm 0.02$, attend nonpreferred object AUC: $0.20 \pm 0.02$, paired Wilcoxon signed rank test, $p=0.15)$. However, a point-by-point comparison revealed a significant ( $p<0.05$, uncorrected) object-based attentional modulation between 485 and $560 \mathrm{~ms}$ after stimulus. Although additional frequency bands, such as alpha and beta, have been implicated in attentional processes, we have not examined these here.

\section{Controls for eye movements}

An important question concerns the possible confound of eye movements in the observed attentional effects. As in every spatial attention task, it is important to verify that the gaze was held constant and only the attentional spotlight was shifted in the visual space. This was indeed verified by eye tracking in two of the patients (due to limitations imposed by the clinical setting, eye tracking was possible only in these patients; see Materials and Methods). In both of these patients and in all attentional conditions, fixations outside the borders of the central image were rare $(<10 \%$ of the trials; Fig. 1C). Removing these trials did not significantly change the values of the spatial and object-based attention indices (paired Wilcoxon signed rank test; spatial domain: $p=0.57$; object domain: $p=0.81$ ). It could be argued that the long time window $(50-600 \mathrm{~ms}$ after stimulus onset) that was used in some of the analyses increased the likelihood of including eye movements, which may have differed between the various attentional conditions. Therefore, we reanalyzed the entire dataset, focusing on the core visual response (100-300 ms after stimulus onset). Using this shorter time window mainly affected the percentage of early visual electrodes that showed significant attentional modulation $(45 \%$ in the short time window vs $81 \%$ in the broad time window). This is expected because of the long latencies of attentional modulation in V1/V2 electrodes (Fig. 4B). All the other main findings were replicated with this shorter time window, further rendering an eye movement confound unlikely.

\section{Discussion}

Attentional modulation of broadband HF responses in early visual cortex

Our results provide a clear demonstration that attention significantly modulates broadband HF $(30-90 \mathrm{~Hz})$ responses in early visual cortex, including in V1/V2 (Fig. 4). In contrast, as shown by previous research (Luck and Girelli, 1998; Martinez et al., 1999; Yoshor et al., 2007; Chalk et al., 2010), VEPs failed to show such modulation (Fig. 8). In this aspect, our results extend a growing body of literature pointing to broadband HF power modulations as a robust neuronal index of perceptual phenomena in general (Singer and Gray, 1995; Tallon-Baudry and Bertrand, 1999; Lachaux et al., 2005; Fisch et al., 2009) and of selective attention in particular (Ray et al., 2008; Lachaux and Ossandón, 2009). It should be stressed that this study focused on broadband spectral modulations and not rhythmic narrow-band gamma synchronization (Fries et al., 2001; Womelsdorf and Fries, 2011; Bosman et al., 2012; Buzsáki et al., 2012). Several recent ECoG studies pointed to discrepancies between broadband HF responses and VEPs (Engell and McCarthy, 2010, 2011; Vidal et al., 2010; Privman et al., 2011). Specifically, Engell and McCarthy (2010) reported a similar phenomenon in high-order visual cortex, namely, that object-based attention strongly modulates face-specific broadband HF responses but not face-specific VEPs (N200). The reason for these discrepancies is not fully established. It has been suggested that VEPs depend on precise 
neuronal phase locking and might be less related to neuronal activity levels (Privman et al., 2011). In addition, our observation that the VEPs showed clear spatial and object selectivity despite the lack of attentional modulation (Fig. 8) suggests that they are driven primarily by bottom-up processes.

The significant attentional modulation of broadband HF responses in early visual cortex reported here is compatible with extensive fMRI literature (Brefczynski and DeYoe, 1999; Gandhi et al., 1999; Kastner et al., 1999; Martinez et al., 1999; Somers et al., 1999). Moreover, the magnitude of the spatial attention modulation in our study was quantified in a similar manner to previous fMRI studies (see Materials and Methods) and paralleled the magnitudes reported in some of these studies (O'Connor et al., 2002). However, it should be noted that several fMRI studies reported attentional effects in early visual cortex during the prestimulus baseline (Kastner et al., 1999; Ress et al., 2000; Silver et al., 2007) that were not found in the current study.

Our results may appear to contrast single-unit and local field recordings in the macaque, reporting modest (Mehta et al., 2000; Maunsell and Cook, 2002; Reynolds and Chelazzi, 2004) or even nonexistent (Luck et al., 1997; Marcus and Van Essen, 2002) attentional modulation of earliest visual areas. However, other studies reported significant attentional modulations in early visual cortex (Roelfsema et al., 1998; Fries et al., 2002; Buffalo et al., 2010; Buffalo et al., 2011; Bosman et al., 2012). A recent study has reported that attention actually reduces gamma-band responses in V1 (Chalk et al., 2010). In contrast, with one exception, in all early visual electrodes that we examined, attention always enhanced the broadband HF response (Fig. 3). There are a few possible explanations for this inconsistency. First, Chalk et al. (2010) (as well as other studies) examined narrow-band gamma responses $(30-50 \mathrm{~Hz})$, selected according to a discrete spectral peak, whereas the current study examined broadband power modulations. Second, there is a major difference in the recording methodology, penetrating microelectrodes in monkey studies versus surface electrodes of $2 \mathrm{~mm}$ in our study (Boynton, 2011). Another important difference concerns the visual stimuli; in the Chalk et al. (2010) study, the stimuli were highly localized line stimuli, whereas in our study the stimuli extended in visual space and consisted of complex object images, probably masking potential surround inhibitory effects (Chalk et al., 2010). Fourth, the differences may result from the fact that behaving primates performed the tasks after long training procedures (usually a few months) whereas the patients underwent brief training only (a few minutes). Long training might reduce the difficulty of the task at hand and thus weaken the attentional modulation (Chen et al., 2008). Finally, one cannot rule out the possibility that a species difference may underlie the differential efficacy of attentional modulations (Boynton, 2011).

Up to this point, we interpreted the attentional modulation effects as enhanced response when the preferred stimulus (either location or object category) was attended. However, we cannot exclude the possibility that the attention effects also reflected a suppression of the response to the nonattended stimulus. Resolving this issue would require a good estimate of baseline activity, which was not available in this study due to the short interblock intervals.

\section{Attentional modulation and functional selectivity}

Our results clearly demonstrate that attention acts to enhance the sensitivity of cortical sites to their preferred stimuli. Thus, across the entire visual hierarchy, the direction of attentional modulation matched the preferred stimulus of the electrodes ( $82 \%$ of the electrodes in the spatial domain and 100\% in the object domain; Figs. 3, 5). Furthermore, there was a clear correlation between the stimulus selectivity of the electrodes and their attentional modulation level both in the spatial domain $(r=0.58, p<0.0005$; Fig. $3)$ and in the object domain $\left(r=0.93, p<10^{-8}\right.$; Fig. 5). This link between stimulus selectivity and attention is compatible with prevailing models of attentional modulations that posit that attention acts to change the gain of stimulus-selective neurons (Moran and Desimone, 1985; Reynolds et al., 2000; Maunsell and Treue, 2006) and with the normalization model of attention (Reynolds and Heeger, 2009). Our results extend these models by demonstrating that the link between receptive field properties and attentional modulation is valid not only to firing rates of individual neurons but also to the activity of large neuronal populations underlying broadband HF responses in ECoG.

An interesting observation of the present study is the finding of clear instances of attentional modulation by eccentricity or size in high-order object-selective electrodes (Fig. 6). Although ventral stream areas have been traditionally assumed to be size and position invariant, a growing number of studies indicate that such complete invariance has been an oversimplification (Levy et al., 2001; Hasson et al., 2003; Yue et al., 2011). Our results are also compatible with previous fMRI studies that demonstrated spatial attention effects in high-order visual areas (Kastner et al., 1998; Martinez et al., 1999; Downing et al., 2001). However, these studies focused on visual hemifield effects (i.e., attend left vs right visual fields), whereas our study extends these observation to the size/eccentricity dimension (i.e., attending the center or the periphery of the visual field).

\section{Attention and the cortical hierarchy}

Our experimental paradigm, combining both spatial and objectbased attention in the same task, allowed us to obtain a direct comparison of such effects across the visual hierarchy. Using the anatomical distance from the occipital pole and response latency as indirect measures of the cortical hierarchy (Tootell et al., 1996; Grill-Spector and Malach, 2004; Murphey et al., 2009), we found that early visual cortex sites were predominately modulated by spatial attention (attending center vs periphery), whereas highorder visual sites were modulated by object-based attention (attending faces vs houses). Comparing the stimulus selectivity of early versus high-order electrodes clearly indicated the dominance of eccentricity selectivity in early cortex and objectcategory selectivity in high-order areas. However, such differential selectivity profiles may be the result of methodological limitations inherent in the fairly large size of the ECoG electrodes, which may average out small functional mosaics, such as feature-selective columns in early visual cortex, while maintaining selectivity for larger scale cortical organizations, such as eccentricity mapping.

In considering the relationship between the cortical hierarchy and attentional modulation, our results clearly confirm and extend prior reports indicating that attentional modulation increases with cortical hierarchy (Moran and Desimone, 1985; Luck et al., 1997; O'Connor et al., 2002). However, previous studies have not differentiated between increases in attentional modulation per se versus increases that result from enhanced functional selectivity. Here we introduced the "effective attentional modulation" measure (attentional modulation divided by stimulus modulation), which showed a gradual increase along the visual cortical hierarchy (Fig. 7). We have argued previously (Avidan et al., 2002) that the visual cortical hierarchy reflects a gradual transformation from optically driven representations to 
more perceptually based ones (Grill-Spector et al., 2000). To the extent that attention modulates the perceptual state, such gradual change in its efficacy along the cortical hierarchy is compatible with this notion.

A major advantage in ECoG recordings over fMRI is the high temporal resolution, which allowed us to uncover the precise timing of the attentional modulation effects. Relating the latency of the attentional effect to the cortical hierarchy revealed that, within early visual cortex, attentional modulation latency was shorter in anterior relative to posterior sites (Fig. 4B). This result is compatible with a recent study in behaving monkeys (Buffalo et al., 2010), which suggested that attentional signals progress backwards from V4 to V1/V2. Our results support this notion and extend these results to human local field potentials recordings. Such progression, together with our failure to detect baseline shifts anticipating the attentional effects, suggests that the attentional modulation was generated de novo for each stimulus presentation, rather than being a sustained modulation throughout the block of trials.

\section{References}

Avidan G, Harel M, Hendler T, Ben-Bashat D, Zohary E, Malach R (2002) Contrast sensitivity in human visual areas and its relationship to object recognition. J Neurophysiol 87:3102-3116. Medline

Avidan G, Levy I, Hendler T, Zohary E, Malach R (2003) Spatial vs object specific attention in high-order visual areas. Neuroimage 19:308-318. CrossRef Medline

Benjamini Y, Hochberg Y (1995) Controlling the false discovery rate: a practical and powerful approach to multiple testing. J R Stat Soc B 57: 289-300.

Bosman CA, Schoffelen JM, Brunet N, Oostenveld R, Bastos AM, Womelsdorf T, Rubehn B, Stieglitz T, De Weerd P, Fries P (2012) Attentional stimulus selection through selective synchronization between monkey visual areas. Neuron 75:875-888. CrossRef Medline

Boynton GM (2011) Spikes, BOLD, attention, and awareness: a comparison of electrophysiological and fMRI signals in V1. J Vis 11:12. CrossRef Medline

Brefczynski JA, DeYoe EA (1999) A physiological correlate of the "spotlight" of visual attention. Nat Neurosci 2:370-374. CrossRef Medline

Buffalo EA, Fries P, Landman R, Liang H, Desimone R (2010) A backward progression of attentional effects in the ventral stream. Proc Natl Acad Sci U S A 107:361-365. CrossRef Medline

Buffalo EA, Fries P, Landman R, Buschman TJ, Desimone R (2011) Laminar differences in gamma and alpha coherence in the ventral stream. Proc Natl Acad Sci U S A 108:11262-11267. CrossRef Medline

Burns SP, Xing D, Shapley RM (2010) Comparisons of the dynamics of local field potential and multiunit activity signals in macaque visual cortex. J Neurosci 30:13739-13749. CrossRef Medline

Buzsáki G, Anastassiou CA, Koch C (2012) The origin of extracellular fields and currents: EEG, ECoG, LFP and spikes. Nat Rev Neurosci 13:407-420. CrossRef Medline

Chalk M, Herrero JL, Gieselmann MA, Delicato LS, Gotthardt S, Thiele A (2010) Attention reduces stimulus-driven gamma frequency oscillations and spike field coherence in V1. Neuron 66:114-125. CrossRef Medline

Chen Y, Martinez-Conde S, Macknik SL, Bereshpolova Y, Swadlow HA, Alonso JM (2008) Task difficulty modulates the activity of specific neuronal populations in primary visual cortex. Nat Neurosci 11:974-982. CrossRef Medline

Crone NE, Sinai A, Korzeniewska A (2006) High-frequency gamma oscillations and human brain mapping with electrocorticography. Prog Brain Res 159:275-295. CrossRef Medline

Delorme A, Makeig S (2004) EEGLAB: an open source toolbox for analysis of single-trial EEG dynamics including independent component analysis. J Neurosci Methods 134:9-21. CrossRef Medline

DeYoe EA, Carman GJ, Bandettini P, Glickman S, Wieser J, Cox R, Miller D, Neitz J (1996) Mapping striate and extrastriate visual areas in human cerebral cortex. Proc Natl Acad Sci U S A 93:2382-2386. CrossRef Medline

Downing P, Liu J, Kanwisher N (2001) Testing cognitive models of visual attention with fMRI and MEG. Neuropsychologia 39:1329-1342. CrossRef Medline

Engell AD, McCarthy G (2010) Selective attention modulates face-specific induced gamma oscillations recorded from ventral occipitotemporal cortex. J Neurosci 30:8780-8786. CrossRef Medline

Engell AD, McCarthy G (2011) The relationship of gamma oscillations and face-specific ERPs recorded subdurally from occipitotemporal cortex. Cereb Cortex 21:1213-1221. CrossRef Medline

Engell AD, Huettel S, McCarthy G (2012) The fMRI BOLD signal tracks electrophysiological spectral perturbations, not event-related potentials. Neuroimage 59:2600-2606. CrossRef Medline

Fisch L, Privman E, Ramot M, Harel M, Nir Y, Kipervasser S, Andelman F, Neufeld MY, Kramer U, Fried I, Malach R (2009) Neural "ignition": enhanced activation linked to perceptual awareness in human ventral stream visual cortex. Neuron 64:562-574. CrossRef Medline

Fries P, Reynolds JH, Rorie AE, Desimone R (2001) Modulation of oscillatory neuronal synchronization by selective visual attention. Science 291: 1560-1563. CrossRef Medline

Fries P, Schröder JH, Roelfsema PR, Singer W, Engel AK (2002) Oscillatory neuronal synchronization in primary visual cortex as a correlate of stimulus selection. J Neurosci 22:3739-3754. Medline

Gandhi SP, Heeger DJ, Boynton GM (1999) Spatial attention affects brain activity in human primary visual cortex. Proc Natl Acad Sci U S A 96: 3314. CrossRef Medline

Grill-Spector K, Malach R (2004) The human visual cortex. Annu Rev Neurosci 27:649-677. CrossRef Medline

Grill-Spector K, Kushnir T, Hendler T, Malach R (2000) The dynamics of object-selective activation correlate with recognition performance in humans. Nat Neurosci 3:837-843. CrossRef Medline

Hasson U, Harel M, Levy I, Malach R (2003) Large-scale mirror-symmetry organization of human occipito-temporal object areas. Neuron 37:10271041. CrossRef Medline

Kanwisher N, Wojciulik E (2000) Visual attention: insights from brain imaging. Nature Rev Neurosci 1:91-100. CrossRef Medline

Kastner S, De Weerd P, Desimone R, Ungerleider LG (1998) Mechanisms of directed attention in the human extrastriate cortex as revealed by functional MRI. Science 282:108-111. CrossRef Medline

Kastner S, Pinsk MA, De Weerd P, Desimone R, Ungerleider LG (1999) Increased activity in human visual cortex during directed attention in the absence of visual stimulation. Neuron 22:751-761. CrossRef Medline

Kreiman G, Hung CP, Kraskov A, Quiroga RQ, Poggio T, DiCarlo JJ (2006) Object selectivity of local field potentials and spikes in the macaque inferior temporal cortex. Neuron 49:433-445. CrossRef Medline

Lachaux J, Ossandón T (2009) Intracortical recordings during attentional tasks. In: From attention to goal-directed behavior: neurodynamical, methodological and clinical trends (Aboitiz F, Cosmelli D, eds), pp 29 49. Berlin: Springer.

Lachaux JP, George N, Tallon-Baudry C, Martinerie J, Hugueville L, Minotti L, Kahane P, Renault B (2005) The many faces of the gamma band response to complex visual stimuli. Neuroimage 25:491-501. CrossRef Medline

Levy I, Hasson U, Avidan G, Hendler T, Malach R (2001) Center-periphery organization of human object areas. Nat Neurosci 4:533-539. CrossRef Medline

Luck SJ, Girelli M (1998) Electrophysiological approaches to the study of selective attention in the human brain. In: The attentive brain (Parasuraman R, ed), pp 71-94. Boston: MIT.

Luck SJ, Chelazzi L, Hillyard SA, Desimone R (1997) Neural mechanisms of spatial selective attention in areas $\mathrm{V} 1, \mathrm{~V} 2$, and $\mathrm{V} 4$ of macaque visual cortex. J Neurophysiol 77:24-42. Medline

Manning JR, Jacobs J, Fried I, Kahana MJ (2009) Broadband shifts in local field potential power spectra are correlated with single-neuron spiking in humans. J Neurosci 29:13613-13620. CrossRef Medline

Marcus DS, Van Essen DC (2002) Scene segmentation and attention in primate cortical areas V1 and V2. J Neurophysiol 88:2648-2658. CrossRef Medline

Martínez A, Anllo-Vento L, Sereno MI, Frank LR, Buxton RB, Dubowitz DJ, Wong EC, Hinrichs H, Heinze HJ, Hillyard SA (1999) Involvement of striate and extrastriate visual cortical areas in spatial attention. Nat Neurosci 2:364-369. CrossRef Medline

Maunsell JH, Cook EP (2002) The role of attention in visual processing. Philos Trans R Soc Lond B Biol Sci 357:1063-1072. CrossRef Medline 
Maunsell JH, Treue S (2006) Feature-based attention in visual cortex. Trends Neurosci 29:317-322. CrossRef Medline

Mehta AD, Ulbert I, Schroeder CE (2000) Intermodal selective attention in monkeys: I. Distribution and timing of effects across visual areas. Cereb Cortex 10:343-358. CrossRef Medline

Miller KJ, Sorensen LB, Ojemann JG, den Nijs M (2009) Power-law scaling in the brain surface electric potential. PLoS Comput Biol 5:e1000609. CrossRef Medline

Moran J, Desimone R (1985) Selective attention gates visual processing in the extrastriate cortex. Science 229:782-784. CrossRef Medline

Murphey DK, Maunsell JH, Beauchamp MS, Yoshor D (2009) Perceiving electrical stimulation of identified human visual areas. Proc Natl Acad Sci U S A 106:5389-5393. CrossRef Medline

Nir Y, Fisch L, Mukamel R, Gelbard-Sagiv H, Arieli A, Fried I, Malach R (2007) Coupling between neuronal firing rate, gamma LFP, and BOLD fMRI is related to interneuronal correlations. Curr Biol 17:1275-1285. CrossRef Medline

O'Connor DH, Fukui MM, Pinsk MA, Kastner S (2002) Attention modulates responses in the human lateral geniculate nucleus. Nat Neurosci 5:1203-1209. CrossRef Medline

O'Craven KM, Downing PE, Kanwisher N (1999) fMRI evidence for objects as the units of attentional selection. Nature 401:584-587. CrossRef

Privman E, Nir Y, Kramer U, Kipervasser S, Andelman F, Neufeld MY, Mukamel R, Yeshurun Y, Fried I, Malach R (2007) Enhanced category tuning revealed by intracranial electroencephalograms in high-order human visual areas. J Neurosci 27:6234-6242. CrossRef Medline

Privman E, Fisch L, Neufeld MY, Kramer U, Kipervasser S, Andelman F, Yeshurun Y, Fried I, Malach R (2011) Antagonistic relationship between gamma power and visual evoked potentials revealed in human visual cortex. Cereb Cortex 21:616-624. CrossRef Medline

Ray S, Maunsell JH (2011) Different origins of gamma rhythm and highgamma activity in macaque visual cortex. PLoS Biol 9:e1000610. CrossRef Medline

Ray S, Niebur E, Hsiao SS, Sinai A, Crone NE (2008) High-frequency gamma activity $(80-150 \mathrm{~Hz})$ is increased in human cortex during selective attention. Clin Neurophysiol 119:116-133. CrossRef Medline

Ress D, Backus BT, Heeger DJ (2000) Activity in primary visual cortex predicts performance in a visual detection task. Nat Neurosci 3:940-945. CrossRef Medline

Reynolds JH, Chelazzi L (2004) Attentional modulation of visual processing. Annu Rev Neurosci 27:611-647. CrossRef Medline

Reynolds JH, Heeger DJ (2009) The normalization model of attention. Neuron 61:168-185. CrossRef Medline

Reynolds JH, Pasternak T, Desimone R (2000) Attention increases sensitivity of V4 neurons. Neuron 26:703-714. CrossRef Medline
Roelfsema PR, Lamme VA, Spekreijse H (1998) Object-based attention in the primary visual cortex of the macaque monkey. Nature 395:376-381. CrossRef Medline

Sereno MI, Dale AM, Reppas JB, Kwong KK, Belliveau JW, Brady TJ, Rosen BR, Tootell RB (1995) Borders of multiple visual areas in humans revealed by functional magnetic resonance imaging. Science 268:889-893. CrossRef Medline

Silver MA, Ress D, Heeger DJ (2007) Neural correlates of sustained spatial attention in human early visual cortex. J Neurophysiol 97:229-237. CrossRef Medline

Singer W, Gray CM (1995) Visual feature integration and the temporal correlation hypothesis. Annu Rev Neurosci 18:555-586. CrossRef Medline

Somers DC, Dale AM, Seiffert AE, Tootell RB (1999) Functional MRI reveals spatially specific attentional modulation in human primary visual cortex. Proc Natl Acad Sci U S A 96:1663-1668. CrossRef Medline

Talairach J, Tournoux P (1988) Co-planar stereotaxic atlas of the human brain: 3-dimensional proportional system. In: An approach to cerebral imaging. New York: Thieme.

Tallon-Baudry C, Bertrand O (1999) Oscillatory gamma activity in humans and its role in object representation. Trends Cogn Sci 3:151-162. CrossRef Medline

Tallon-Baudry C, Bertrand O, Hénaff MA, Isnard J, Fischer C (2005) Attention modulates gamma-band oscillations differently in the human lateral occipital cortex and fusiform gyrus. Cereb Cortex 15:654-662. CrossRef Medline

Tootell RB, Dale AM, Sereno MI, Malach R (1996) New images from human visual cortex. Trends Neurosci 19:481-489. CrossRef Medline

Van Essen DC, Drury HA, Dickson J, Harwell J, Hanlon D, Anderson CH (2001) An integrated software suite for surface-based analyses of cerebral cortex. J Am Med Inform Assoc 8:443-459. CrossRef Medline

Vidal JR, Ossandón T, Jerbi K, Dalal SS, Minotti L, Ryvlin P, Kahane P, Lachaux JP (2010) Category-specific visual responses: an intracranial study comparing gamma, beta, alpha, and ERP response selectivity. Front Hum Neurosci 4:195. CrossRef Medline

Womelsdorf T, Fries P (2011) Rhythmic neuronal synchronization subserves selective attention processing. In: Characterizing Consciousness: From Cognition to the Clinic (Dehaene S, Christen Y, eds), pp 109-132. Berlin: Springer. CrossRef

Yoshor D, Ghose GM, Bosking WH, Sun P, Maunsell JH (2007) Spatial attention does not strongly modulate neuronal responses in early human visual cortex. J Neurosci 27:13205-13209. CrossRef Medline

Yue X, Cassidy BS, Devaney KJ, Holt DJ, Tootell RB (2011) Lower-level stimulus features strongly influence responses in the fusiform face area. Cereb Cortex 21:35-47. CrossRef Medline 